\title{
Acoustic emission based condition monitoring study of piston rod seals by varying speed and pressure parameters
}

\author{
Vignesh. V. Shanbhag ${ }^{1}$, Thomas. J. J. Meyer ${ }^{2}$, Leo. W. Caspers ${ }^{3}$ and Rune Schlanbusch ${ }^{4}$ \\ ${ }^{1,2,4}$ Norwegian Research Centre, Jon Lilletuns Vei 9 H, 3. etg, 4879, Grimstad, Norway \\ vigs@norceresearch.no \\ thme@norceresearch.no \\ rusc@norceresearch.no
}

${ }^{3}$ Bosch Rexroth B.V., Kruisbroeksestraat 1, 5281 RV, Boxtel, The Netherlands

leo.caspers@boschrexroth.nl

\begin{abstract}
Seal wear is one of the primitive causes of failure in hydraulic cylinders. Regular visual inspection of seals without affecting the productivity is difficult as the seals are placed internally in the hydraulic cylinder requiring disassembly of the piston. Therefore, condition monitoring is required to assess the current health of the seals. There have been successful attempts made in literature for the assessment of seal quality using acoustic emission-based condition monitoring. However, there have been very few acoustic emission-based condition monitoring studies performed to diagnose the seal failure under varying speed and pressure parameters. Therefore, this study aims at increasing the understanding of seal failure under varying speed and pressure conditions through correlation with the acoustic emission features. Experiments were performed on a hydraulic test rig using unworn and worn piston rod seals. For each seal wear condition, experiments were performed for five strokes at pressure conditions of 10,20,30 and 40 bar and piston rod speed of $50 \mathrm{~mm} / \mathrm{s}$ and $100 \mathrm{~mm} / \mathrm{s}$. To reduce the noise from other machine parts in the test rig, the acoustic emission signal of each piston rod stroke was filtered using a bandpass filter. The acoustic emission signal before and after bandpass filtering was analyzed using different acoustic emission time and frequency domain features. For unworn and worn piston rod seal conditions, the acoustic emission features obtained from the acoustic emission signal after bandpass filtering have good separability and low variability when compared to the acoustic emission features obtained from the non-filtered data. Therefore, the acoustic emission-based condition monitoring methodology developed in this study lays a strong
\end{abstract}

Vignesh. V. Shanbhag et al. This is an open-access article distributed under the terms of the Creative Commons Attribution 3.0 United States License, which permits unrestricted use, distribution, and reproduction in any medium, provided the original author and source are credited. foundation for further research to develop real-time monitoring of the piston rod seal in hydraulic cylinders.

Keywords: Piston rod seals, Acoustic emission, Bandpass filter, Speed and Pressure.

\section{INTRODUCTION}

Hydraulic cylinders are widely used in offshore oil and gas $(\mathrm{O} \& \mathrm{G})$ industry for different applications such as material handling, clamping systems and heave compensation. Condition monitoring of hydraulic cylinders is gaining importance in the O\&G industry to prevent the failure of any critical part as to minimize unscheduled maintenance. One of the primitive causes of failure in hydraulic cylinders is fluid leakage due to piston rod seal wear. Leakage in hydraulic cylinders can result in lack of force, variation in speed or instability in the system (Zhao et al. 2015). Detection of the very initial stage of piston rod seal wear by the visual inspection method is difficult due to concealment of the piston rod seal in the cylinder (An et al., 2005 \& Zhao et al., 2015). Therefore, it is important to detect the piston rod seal wear using sensor-based condition monitoring methods that allow active monitoring of the wear-state of the piston rod seal, and thus preventing fluid leakage.

There has been a number of attempts made in literature to study fluid leakage in hydraulic cylinder using different sensor-based condition monitoring methods. For example, Goharrizi et al. (2010) used a wavelet-based approach for analyzing the pressure signal to detect external leakage from a hydraulic actuator. The pressure signal was decomposed into discrete wavelet coefficients. The root mean square (RMS) value of the level 4 coefficient was observed to be sensitive to diagnose external leakage. The scaled RMS value of the level 4 wavelet coefficient under varying leakage conditions are: no leak $=1$, small leak $=0.95$, medium small leak $=0.78$, medium large leak $=0.76$, and large leak $=0.69$. In 
the other work of Goharrizi et al. (2010), the RMS value of the level 2 coefficient was observed to be sensitive to detect internal leakage. To detect normal and internal leakage conditions, a baseline of RMS value 30 was defined. During internal leakage conditions, the RMS values stayed below 30, for $90 \%$ of the time. The indices were able to detect external leakage as low as $0.3 \mathrm{~L} / \mathrm{min}$ and internal leakage as low as $0.2 \mathrm{~L} / \mathrm{min}$ with sensitivity (probability of detection) of $90 \%$. An et al. (2005) applied the extended Kalman filter technique to the pressure signal to monitor external and internal leakage from a hydraulic cylinder. The residual error feature obtained from monitoring chamber pressure was proposed to monitor fluid leakage. With an increase in leakage the magnitude of the residual error increased proportionally. Tang et al. (2010) used the wavelet method with a backpropagation neural network to determine features from the pressure signal that can be used to monitor fluid leakage from the hydraulic cylinder. The energy feature obtained from the frequency bands after wavelet decomposition was composed in the form of an eigen vector. These eigen vectors were later fed as input to the backpropagation network to classify the faults. Using this method, it was possible to identify non-leakage, mild leakage and severe leakage faults. Similarly, Zhao et al. (2015) used wavelet packet analysis to extract features from the inlet and outlet of the pressure signal that can be used to monitor leakage from a hydraulic cylinder. The displacement signal of the piston rod was also used to monitor severity in leakage. The wavelet packet energy variance, wavelet energy of coefficient 1 in level 4, wavelet entropy feature, pressure rising speed and piston rod stretching speed were proposed to monitor the leakage. Tan et al. (2000 \& 2003) used vibration measurements to understand the vibration signatures from reciprocating machinery such as hydraulic cylinders. From the vibration data analysis, it was observed that removal of the piston seal in the hydraulic cylinder studied lead to an increase in amplitude at a frequency of $48.8 \mathrm{~Hz}$ and with the piston seal installed in the hydraulic cylinder the frequency peak was observed at $96.6 \mathrm{~Hz}$ in the amplitude-frequency spectrum. Chen et al. (2007) studied the seal integrity in the hydraulic cylinder using acoustic emission (AE). Different AE features such as power spectral density (PSD), AE count, AE RMS were used to monitor the internal fluid leakage from the hydraulic cylinder. The AE features based on energy such as RMS were observed to be sensitive compared to other $\mathrm{AE}$ features such as AE count or peak of PSD to monitor the internal fluid leakage. The AE RMS feature was observed to be sensitive mainly after leakage rate of $0.3 \mathrm{~L} / \mathrm{min}$. At internal leakage rate of $0.35 \mathrm{~L} / \mathrm{min}$, the $\mathrm{AE} \mathrm{RMS}$ value was observed to be $0.02 \mathrm{~V}$ and at internal leakage rate of 0.82 $\mathrm{L} / \mathrm{min}$, the AE RMS value was observed to be $0.85 \mathrm{~V}$. The correlation coefficient value between AE RMS and internal leakage rate was observed to be 0.9654 . There have also been attempts to monitor faults in hydraulic motors using different sensor-based condition monitoring methods. For example, Chen et al. (2008) used the wavelet technique to analyse the AE signal from a hydraulic motor. The wavelet spectrum analyzed in between $5.5-7 \mathrm{kHz}$ was observed to be sensitive to faults compared to conventional PSD. Also, the RMS feature of the AE signal obtained from wavelet analysis was proposed to monitor piston crack under different flow rates and torque. Ramachandran et al. (2018), used a torque sensor to monitor seal degradation in rotating machinery. Different time domain features were used to monitor seal degradation. RMS, peak, mean and squared mean rooted absolute amplitude features of the torque signal were observed to be sensitive to seal degradation over time. In the other work, Ramachandran et al. (2019) used a multi-layer perceptron network to classify torque features related to unworn, semiworn, worn and completely failed seal. From literature, we can observe that there have been successful attempts to monitor seal wear in hydraulic cylinders or hydraulic motors using different sensor-based condition monitoring methods. However, there have been limited attempts to monitor seal wear from the hydraulic cylinder under varying speed and pressure parameters. Therefore, in this study, an AE based condition monitoring study is adopted to monitor seal wear in the hydraulic cylinder under different speed and pressure conditions. The AE method is mainly chosen because of its broad frequency range and its ability to diagnose the failure in machine parts at very initial stages (Shanbhag et al. 2019).

To study the seal wear using AE, experiments were performed on a hydraulic test rig at different pressure and speed conditions. Because of noise, generated by components of the test rig other than the piston rod seal, the AE signal from each stroke was filtered using a bandpass filter. The unfiltered and filtered AE signals were analyzed using different $\mathrm{AE}$ features to understand the sensitivity of $\mathrm{AE}$ features to diagnose the seal wear at varying pressure and speed conditions.

\section{Methodology}

\subsection{Experimental details}

A custom built test rig was used to study the piston rod seal wear at different pressure and speed conditions. As shown in Figure 1-a), the test rig consists of an electro-mechanical cylinder with a hydraulic cylinder head. The leakage observed from the test rig closely replicates the typical leakage that is observed in a hydraulic cylinder. The extension and retraction stroke of the piston rod through the cylinder head is driven by a spindle and nut that converts rotational motion of the servomotor to translational motion of the piston rod. The cylinder head is a pressurized flange that contains three bearing strips to withstand arising transversal loads and seals to prevent fluid leakage (Figure 1-b)). Transversal load was not applied in this study. The pressurized fluid within the cylinder head is supplied through a hydraulic power pack and the pressure is controlled by a pressure control valve. An encoder present in the servomotor enables the monitoring of the piston rod position and the recording of the number of times the piston rod passed 
through the cylinder head. The test rig is at rest for one second at the end of each extension and retraction stroke to allow the segregation of sensor signal. The length of the extension and retraction strokes are $600 \mathrm{~mm}$.

To perform condition monitoring studies only the top seal from the cylinder head was replaced with unworn and worn seals (Figure 1-b)). The unworn seal had no grooves or scratches (Figure 1-c)), whereas the worn seal had major grooves (Figure 1-d)

a)

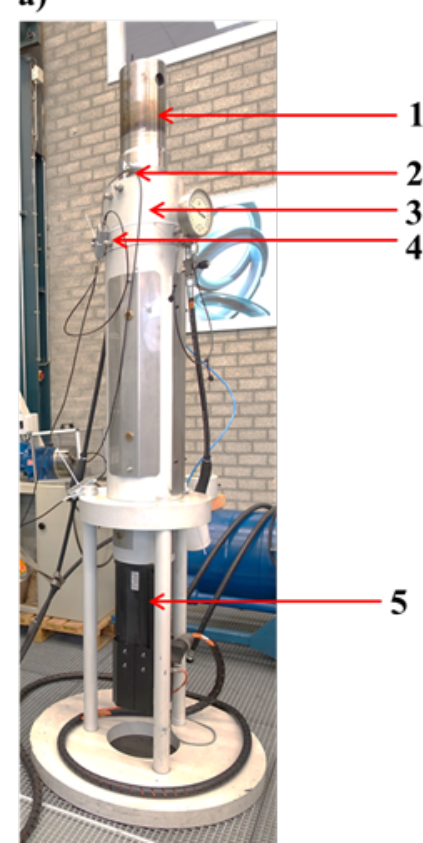

b)

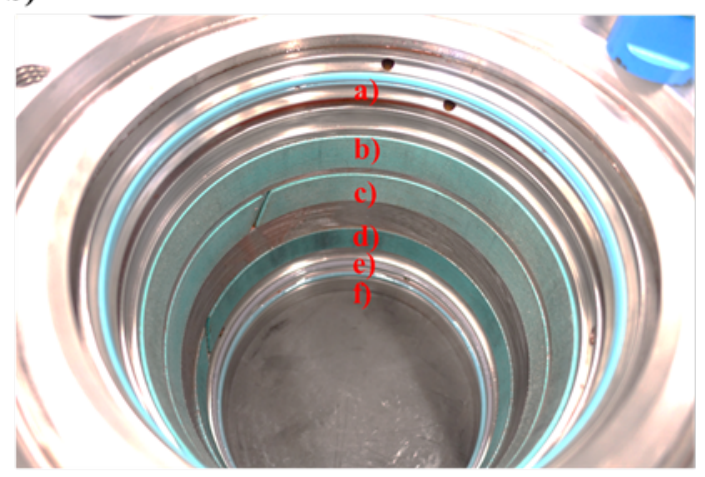

Figure a)

1. Piston rod

2. AE sensor

3. Cylinder head

4. AE pre-amplifier

5. Motor
Figure b)

a) Piston rod seal

b)-d) Bearing strips

e) Primary seal (in white color)

f) Secondary seal c)

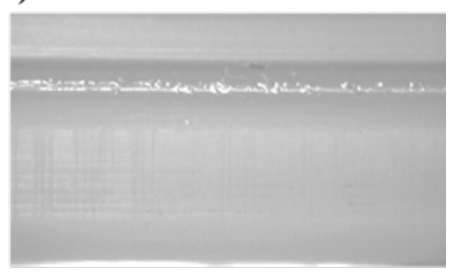

d)

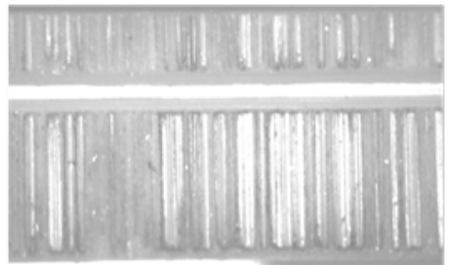

Figure 1. a) Hydraulic test rig b) Piston rod seal and bearing strip arrangement in cylinder head; Microscopic camera images of piston rod seal c) Unworn d) Worn (Note: Instrument used to take close up image of unworn and worn seal: Jenoptik

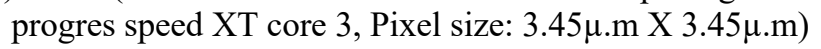

For each seal condition, experiments were performed at pressure conditions of 10, 20,30 and 40 bar and speeds of 50 and $100 \mathrm{~mm} / \mathrm{s}$. Each experiment was performed for five strokes. Remaining process parameters and experimental details such as fluid type, seal type and seal material are summarized in Table 1.

\begin{tabular}{|l|l|}
\hline Piston rod seal type & $\begin{array}{l}\text { Stepseal-2A type (Supplier: Trelleborg } \\
\text { Sealing Solutions) }\end{array}$ \\
\hline Piston rod seal material & $\begin{array}{l}\text { Polyether-based polyurethane elastomer } \\
\text { (Grade: } \mathrm{Z} 52)\end{array}$ \\
\hline Seal size & $180^{*} 195 * 6.3 \mathrm{~mm}$ \\
\hline Coating on piston rod & Cladded coating of a cobalt based alloy \\
\hline Fluid & Water glycol \\
\hline Speed & 50 and $100 \mathrm{~mm} / \mathrm{s}$ \\
\hline Pressure & $10,20,30,40 \mathrm{bar}$ \\
\hline Stroke length & $600 \mathrm{~mm}$ \\
\hline Number of strokes & 5 \\
\hline Seal condition & Unworn and worn seal \\
\hline AE data acquisition & $1 \mathrm{MS} / \mathrm{s}$ \\
\hline AE amplifier gain & $40 \mathrm{~dB}$ \\
\hline
\end{tabular}

\begin{tabular}{|l|l|}
\hline AE frequency range & $50-400 \mathrm{kHz}$ \\
\hline AE resonant frequency & $150 \mathrm{kHz}$ \\
\hline AE pre-amplifier type & $0 / 2 / 4$ gain \\
\hline
\end{tabular}

Table 1. Process parameters

\subsection{AE data acquisition}

The piston rod seal placed in the cylinder head is in, to a certain extend lubricated, contact with the piston rod during the extraction and retraction stroke (Figure 1 a)-b)). Therefore, the AE sensor is mounted on the piston rod to obtain a good transfer of the AE signal (elastic waves) related to the piston rod seal wear. The AE sensor is fixed to the piston rod using an adhesive bond and industrial duct tape. A mid-frequency range $\mathrm{AE}$ sensor (Model: R15 $\alpha$, Supplier: Physical Acoustics) having an operating AE frequency range of $50-400 \mathrm{kHz}$ is used in this study. The AE sensor is connected to a pre-amplifier (Supplier: Physical Acoustics) using a coaxial cable with BNC (Bayonet Neill-Concelman) and microdot connector. The pre-amplifier is connected to a data acquisition setup using a 5 meter-long cable with BNC connectors. For all the experiments, the AE data acquisition and $\mathrm{AE}$ pre-amplifier gain were maintained at $1 \mathrm{MS} / \mathrm{s}$ and 40 
$\mathrm{dB}$, respectively. The continuous AE signal was recorded for each experiment using AEwin software (Supplier: Physical Acoustics).

To ensure a good signal path to the AE sensor, the HsuNielsen pencil lead break test was performed at regular intervals. If the magnitude of the power spectral density in the $\mathrm{AE}$ frequency range of $30-170 \mathrm{kHz}$ (Figure 2) from a pencil lead break was not greater than that of noise (170-500 $\mathrm{kHz}$ ), then the AE sensor was removed and re-fixed with a sufficient amount of adhesive bond.

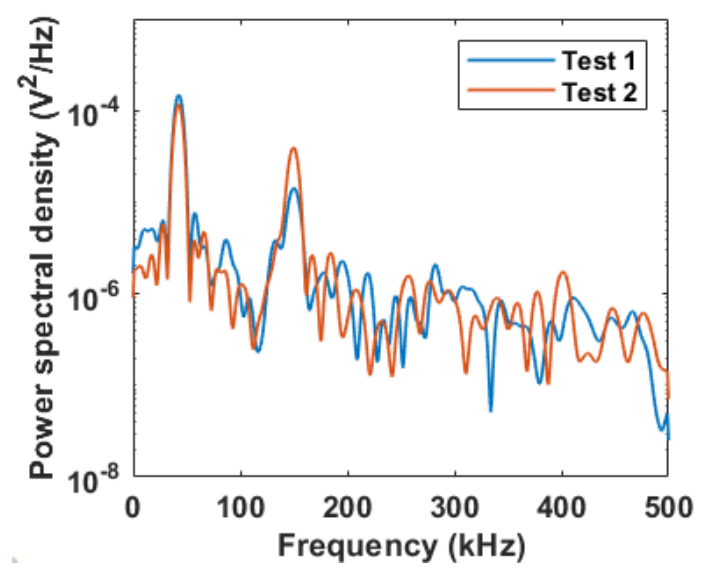

Figure 2. Power spectral density plot of pencil lead break tests (Note: For clarity the y-axis is plotted using log scale)

\subsection{AE analysis}

The AE signal of the extension and retraction strokes was separated based on the timing of the movement. As the content of the AE signal during extension stroke was similar to that of retraction stroke, only the AE signal related to the extension stroke is used for the analysis. To avoid any starting and stopping phenomena in the continuous AE signal, only the second, third and fourth strokes were used for the $\mathrm{AE}$ analysis. Figure 3 represents the methodology adopted for $\mathrm{AE}$ data acquisition and AE analysis. As shown in Figure 1-b), the cylinder head contains three bearing strips along the piston rod seal. The continuous AE signal recorded during the experiment may originate from other machine parts such as the bearing strips, piston rod or the two other piston rod seals. Therefore, the power spectrum of the AE signal was initially analyzed to understand the $\mathrm{AE}$ frequency related to piston rod seal under investigation. Based on this analysis, the observed $\mathrm{AE}$ frequency related to the piston rod seal was used as an input for defining the bandpass filter. The filtered and the unfiltered $\mathrm{AE}$ signals were analyzed using various time domain and frequency domain features. The sensitivity of $\mathrm{AE}$ features obtained from the unfiltered and the filtered $\mathrm{AE}$ signals is studied to understand the $\mathrm{AE}$ features that can be used to identify and separate the unworn and worn seal conditions. AE features such as RMS, peak, kurtosis, bandpower, median frequency and mean frequency were used for the analysis. Mean of three strokes and its standard deviation were calculated for each pressure condition to understand the repeatability of each AE feature that can be used for condition monitoring.

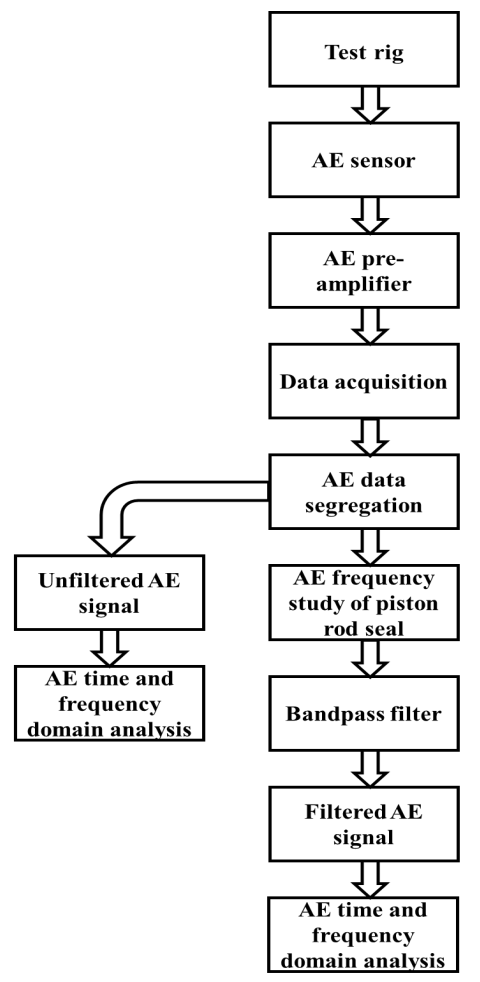

Figure 3. Methodology adopted for AE data acquisition and $\mathrm{AE}$ analysis

\section{EXPERIMENTAL RESULTS}

\subsection{Unfiltered AE signal at different speeds}

There are different types of $\mathrm{AE}$ signals: a) continuous $\mathrm{AE}$ signal, b) burst AE signal and c) combination of burst and continuous AE signal (Terchi et al. 2001 \& Shanbhag et al. 2020). When the test was performed at $50 \mathrm{~mm} / \mathrm{s}$, only a continuous AE signal was observed for the experiments performed using unworn and worn seal (Figure $4 a$ a)-b)). From Figure $4 \mathrm{a}$ )-b), the amplitude of the continuous AE signal for the experiment performed using unworn seal is $\approx 0.2 \mathrm{~V}$ and for the worn seal it is $\approx 0.4 \mathrm{~V}$. For the tests performed at 100 $\mathrm{mm} / \mathrm{s}$, along with the continuous AE signal, a burst AE signal was observed (Figure $4 \mathrm{c}$ )-d)). Due to non-stationary behavior of the $\mathrm{AE}$ signal during the experiments performed at $100 \mathrm{~mm} / \mathrm{s}$, it is not clearly possible to identify and separate the amplitude of the AE signal related to unworn and worn seals. The AE burst signals may be caused by other parts of the system, e.g. the bearing strips present in the cylinder head or the spindle present in the test rig. Therefore, to identify the AE signal related to the piston rod seal wear at $50 \mathrm{~mm} / \mathrm{s}$ and $100 \mathrm{~mm} / \mathrm{s}$, bandpass filtering is performed. 

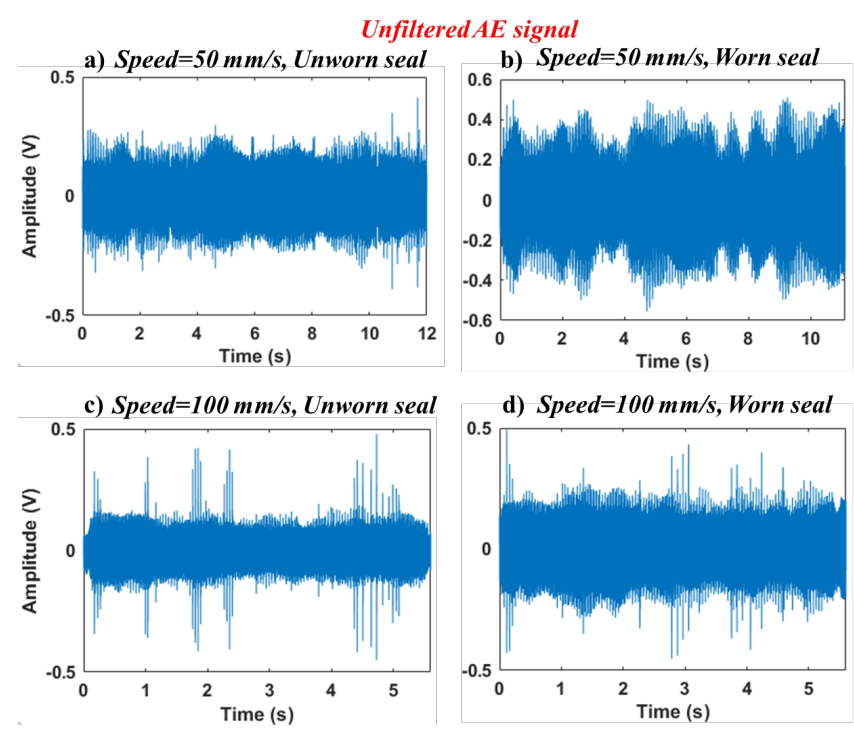

Figure 4. Unfiltered AE signal from test rig observed from a)-b) unworn seal and worn seal at $50 \mathrm{~mm} / \mathrm{s}, \mathrm{c}$ )-d) unworn and worn seal at $100 \mathrm{~mm} / \mathrm{s}$. (Pressure $=20 \mathrm{bar}$, stroke number $=2$, extension stroke AE signal).

\subsection{Power spectrum}

A power spectrum study is performed to determine the $\mathrm{AE}$ frequency related to the piston rod seal wear as input for the bandpass filtering parameters. Figure 5 represents the power spectrum of the AE signal shown in Figure 4 a)-d). Two magnitude peaks in the AE frequency ranges of $0-30 \mathrm{kHz}$ and $50-100 \mathrm{kHz}$ can be observed. These AE magnitude peaks may be caused by other machine parts that are present in the test rig. It is important to note that the $\mathrm{AE}$ frequency distribution is nearly consistent except in the AE frequency range of 50-100 $\mathrm{kHz}$. As the piston rod seal (unworn and worn) was the only part in the test rig that was replaced, the AE frequency distribution related to the piston rod seal wear is assumed to be in the AE frequency range of $50-100 \mathrm{kHz}$. This frequency is thus chosen as the bandpass filter range.
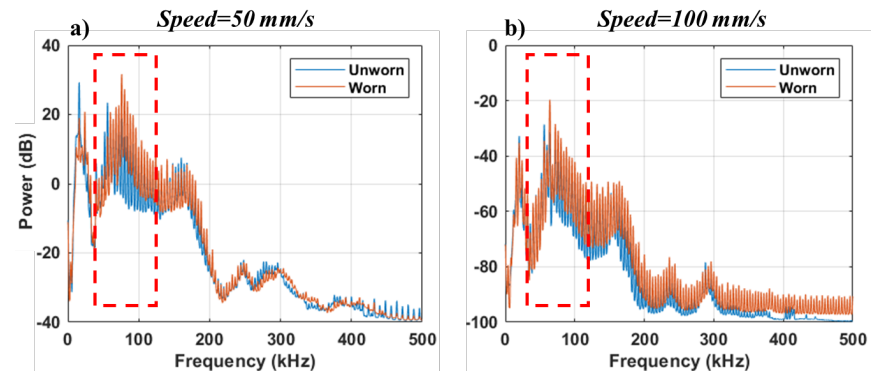

Figure 5. Power spectrum a) $50 \mathrm{~mm} / \mathrm{s} \mathrm{b)} 100 \mathrm{~mm} / \mathrm{s}$. (Pressure $=20$ bar, stroke number $=2$, extension stroke AE signal).

\subsection{Bandpass filtered $\mathrm{AE}$ signal at different speeds}

Figure 6 represents the bandpass filtered AE signal in the AE frequency range of $50-100 \mathrm{kHz}$. Comparing Figure 6 to Figure 4 it can be observed that only the continuous AE signal is observed from the experiments performed at $50 \mathrm{~mm} / \mathrm{s}$ and $100 \mathrm{~mm} / \mathrm{s}$. Also, minimum variation is observed in the $\mathrm{AE}$ signal in Figure $6 \mathrm{c}$ )-d) compared to Figure $4 \mathrm{c}$ )-d). From the bandpass filtered AE signal, it is possible to identify and separate the AE signal related to unworn and worn seals at 50 $\mathrm{mm} / \mathrm{s}$ and $100 \mathrm{~mm} / \mathrm{s}$ using the amplitude range of the $\mathrm{AE}$ continuous signal. At $50 \mathrm{~mm} / \mathrm{s}$, for the unworn seal the $\mathrm{AE}$ amplitude is $\approx 0.2 \mathrm{~V}$, and for the worn seal the AE amplitude is $\approx 0.4 \mathrm{~V}$. Whereas, for the $100 \mathrm{~mm} / \mathrm{s}$, for the unworn seal the $\mathrm{AE}$ amplitude range is $\approx 0.1 \mathrm{~V}$, and for the worn seal the $\mathrm{AE}$ amplitude range is $\approx 0.15 \mathrm{~V}$.
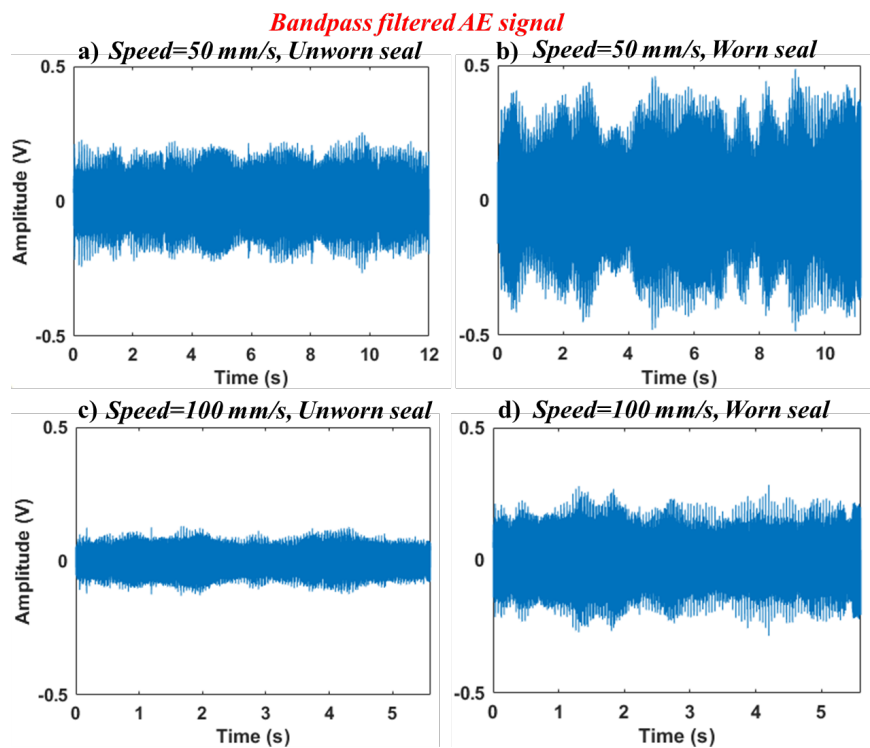

Figure 6. Filtered AE signal from test rig observed from a)b) unworn seal and worn seal at $50 \mathrm{~mm} / \mathrm{s}, \mathrm{c}$ )-d) unworn and worn seal at $100 \mathrm{~mm} / \mathrm{s}$. (Pressure $=20 \mathrm{bar}$, stroke number $=2$, extension stroke AE signal).

\subsection{AE time domain and frequency domain analysis}

Figure 7 represents the AE time domain and frequency domain features analyzed based on the unfiltered AE signal. For the experiments performed at $50 \mathrm{~mm} / \mathrm{s}$, in the time domain features, the AE RMS and peak features can identify unworn and worn conditions of the piston rod seal in the cylinder head (Figure $7 \mathrm{a}$ ), c)). Similarly, for $100 \mathrm{~mm} / \mathrm{s}$, the AE RMS and kurtosis features can identify the difference between the unworn and worn seals. However, the separability between the AE features (RMS and kurtosis) for the unworn and worn piston rod seals is low (Figure $7 \mathrm{a})-\mathrm{b}$ )). In the frequency domain features for the experiments performed at $50 \mathrm{~mm} / \mathrm{s}, \mathrm{AE}$ bandpower, median frequency and mean frequency features can identify the unworn and worn piston rod seal conditions in the cylinder head (Figure $7 \mathrm{~d}$ )- 
f)). The separability of the AE bandpower feature between unworn and worn piston rod seals is low. Similar behavior is also observed for the $\mathrm{AE}$ frequency domain features for the experiments performed at $100 \mathrm{~mm} / \mathrm{s}$ (Figure $7 \mathrm{~d}$ )-f)).

Figure 8 represents the $\mathrm{AE}$ time domain and frequency domain features analyzed using the bandpass filtered $\mathrm{AE}$ signal. For the experiments performed at $50 \mathrm{~mm} / \mathrm{s}$, in the $\mathrm{AE}$ time domain features, the AE RMS, peak and kurtosis can identify and separate the AE features related to unworn and worn piston rod seals in the cylinder head (Figure 8 a)-c)). Among the AE frequency domain features, $\mathrm{AE}$ bandpower and mean frequency can identify and separate the unworn and worn conditions of the piston rod seal in the cylinder head. However, the separability between the unworn and worn seals for the $\mathrm{AE}$ bandpower feature is low compared to the $\mathrm{AE}$ mean frequency feature (Figure $8 \mathrm{~d}$ )-e)). For the experiments, performed at $100 \mathrm{~mm} / \mathrm{s}$, in the AE time domain feature, the AE RMS and peak features can identify and separate the unworn and worn conditions of the piston rod seal in the cylinder head (Figure 8 a), c)). Among the frequency domain features, the $\mathrm{AE}$ bandpower, mean frequency and median frequency features can identify and separate the unworn and worn conditions of the piston rod seal in the cylinder head (Figure $8 \mathrm{~d}$ )-f)).

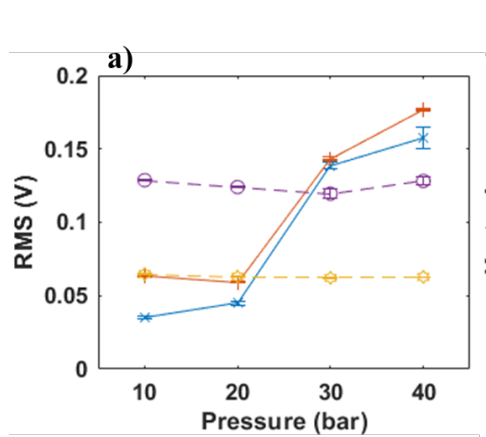

$A E$ analysis using unfiltered $A E$ signal
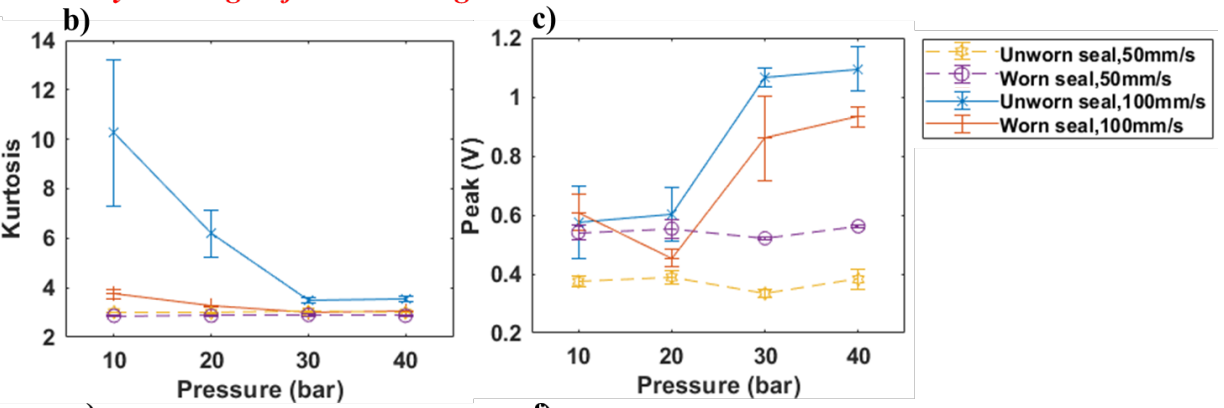

d)
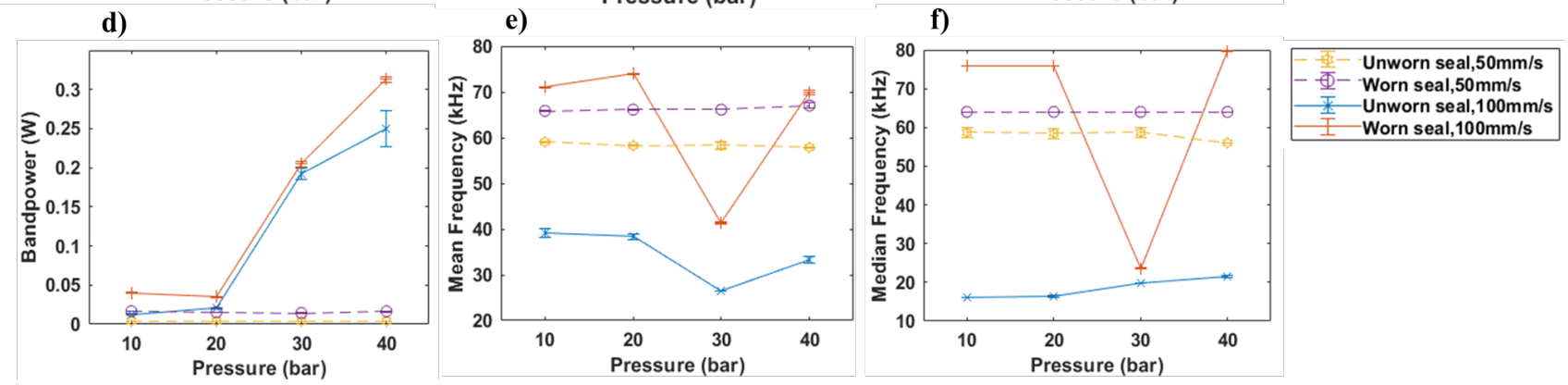

Figure 7. AE time domain features from unfiltered AE signal a) RMS b) Kurtosis c) Peak d) Bandpower e) Mean Frequency f) Median Frequency 


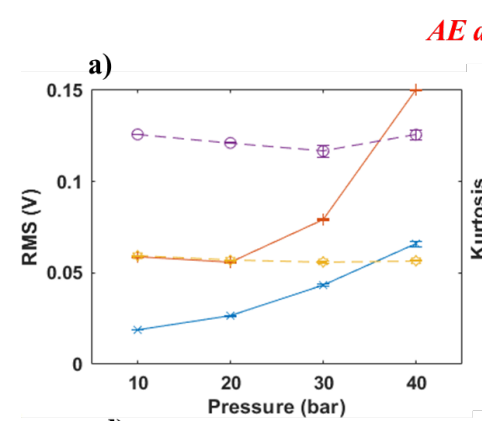

AE analysis using bandpass filtered AE signal
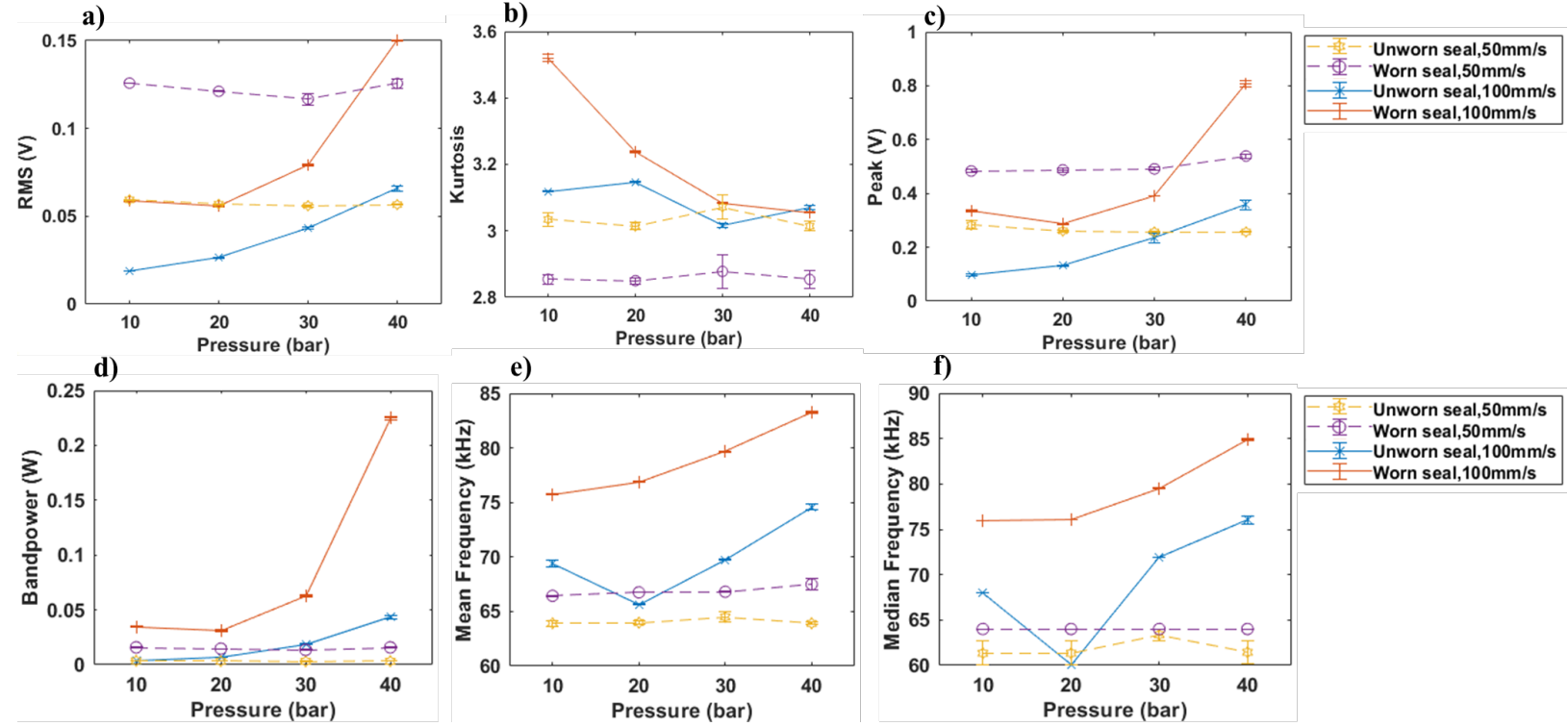

e)
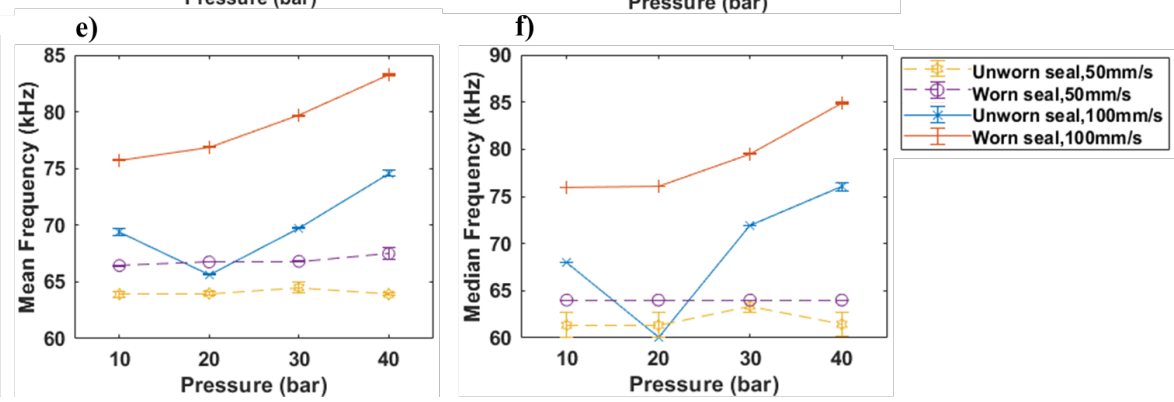

Figure 8. AE time domain features from bandpass filtered AE signal a) RMS b) Kurtosis c) Peak d) Bandpower e) Mean Frequency f) Median Frequency

\section{DISCUSSION}

Table 2 represents the summary of AE features analyzed using unfiltered and bandpass filtered AE signals. From Figure 7 and Figure 8, it is clear that, for the time and frequency domain features, the separability to identify $\mathrm{AE}$ features from bandpass filtered AE signal for unworn and worn seals is higher compared to the AE features analyzed using the unfiltered signal. This is mainly because in the bandpass filtered AE signal there is a minimum interference of $\mathrm{AE}$ frequencies related to other parts present in the test rig (Eftekharnejad et al. 2011). The higher separability of the AE features for the unworn and worn piston rod seal also indicates better sensitivity and reliability. For the experiments performed at $50 \mathrm{~mm} / \mathrm{s}$, the $\mathrm{AE}$ features are nearly stable for all the pressure conditions. Whereas, for the experiments performed at $100 \mathrm{~mm} / \mathrm{s}$, the AE features tend to get unstable with a change in pressure. This unstable behavior of AE features can be attributed to the higher stress generated on the piston rod seal due to the combined effect of pressure and speed. However, irrespective of the speed and pressure conditions, the AE features can clearly identify and separate the AE features related to unworn and worn piston rod seal. For the AE features obtained from the bandpass filtered $\mathrm{AE}$ signal (Figure 8 a), c)-f)), the value of RMS, peak, bandpower, mean frequency and median frequency feature for the worn seal is greater than that of the unworn seal. This is due to the unstable behavior in the cylinder head caused by fluid leakage which results in increase in amplitude and power of the AE signal (Figure 5 and Figure 6). Compared to the condition monitoring studies performed by Zhao et al. (2015) using a pressure sensor and Tan et al. (2003) using a vibration sensor, the energy value of the $\mathrm{AE}$ signal tends to increase in our study for the worn piston rod seal when compared to the unworn piston rod seal (Figure 8-a)). This is likely due to the high working frequency range of the $\mathrm{AE}$ sensor which makes it sensitive to the noise generated by the leakage in the cylinder head (Chen at al. 2007). A linear increase can also be observed with the increase in pressure for AE RMS, peak, bandpower, mean frequency and median frequency (Figure 8). This can be attributed to the higher friction generated between piston rod seal and piston rod and to the increase in leakage of oil from the test rig with the increase in pressure (Chen at al. 2007). AE RMS, peak and mean frequency features had higher separability for unworn and worn seals at all the pressure and speed conditions than the other AE features (Table 2).

\begin{tabular}{|l|c|c|c|c|}
\hline & \multicolumn{2}{|c|}{$\begin{array}{c}\text { Unfiltered AE } \\
\text { signal }\end{array}$} & \multicolumn{2}{c|}{$\begin{array}{c}\text { Bandpass filtered } \\
\text { AE signal }\end{array}$} \\
\hline \multicolumn{1}{|c|}{ Speed } & $\begin{array}{c}\mathbf{5 0} \\
\mathbf{m m} / \mathbf{s}\end{array}$ & $\begin{array}{c}\mathbf{1 0 0} \\
\mathbf{m m} / \mathbf{s}\end{array}$ & $\begin{array}{c}\mathbf{5 0} \\
\mathbf{m m} / \mathbf{s}\end{array}$ & $\begin{array}{c}\mathbf{1 0 0} \\
\mathbf{m m} / \mathbf{s}\end{array}$ \\
\hline RMS & $\checkmark$ & $\checkmark *$ & $\checkmark$ & $\checkmark$ \\
\hline Kurtosis & $\boldsymbol{x}$ & $\checkmark *$ & $\checkmark$ & $\boldsymbol{x}$ \\
\hline Peak & $\checkmark$ & $\boldsymbol{x}$ & $\checkmark$ & $\checkmark$ \\
\hline Bandpower & $\checkmark *$ & $\checkmark *$ & $\checkmark *$ & $\checkmark$ \\
\hline $\begin{array}{l}\text { Mean } \\
\text { frequency }\end{array}$ & $\checkmark$ & $\checkmark$ & $\checkmark$ & $\checkmark$ \\
\hline $\begin{array}{l}\text { Median } \\
\text { Frequency }\end{array}$ & $\checkmark$ & $\checkmark$ & $\checkmark *$ & $\checkmark$ \\
\hline
\end{tabular}

$\checkmark$ - Can identify unworn \& worn seal $x$ - Cannot identify unworn \& worn seal $\checkmark *$-Low separability between the AE features for unworn and worn seal.

Table 2: Summary of AE features 


\section{SUMMARY}

This study investigated the AE features that can be used to detect piston rod seal wear at different pressure and speed conditions in a hydraulic test rig. As the AE signal may originate from different machine parts of the test rig, a bandpass filtering technique was used to filter the AE signal generated by the piston rod seal and rod surface interaction.

1. From the AE power spectrum, the AE frequency range for the piston rod seal wear was observed to be in the AE frequency range of $50-100 \mathrm{kHz}$

2. The AE time domain features obtained from bandpass filtered AE had higher separability for unworn and worn seal when compared to the AE time domain features obtained from unfiltered AE signal.

3. AE RMS, peak and mean frequency features obtained from the bandpass filtered AE signal had higher separability between the unworn and worn seal for all the pressure and speed conditions than the other AE features.

The higher sensitivity and reliability of the AE features observed for AE RMS, peak and mean frequency to identify the unworn and worn piston rod seal in the test rig indicate that these features could be used for real time monitoring of the piston rod seals in hydraulic cylinders in the offshore O\&G industry.

\section{ACKNOWLedgement}

The research presented in this paper has received funding from the Norwegian Research Council, SFI Offshore Mechatronics, project number 237896.

\section{REFERENCES}

An, L. \& Sepehri, N. (2005). Hydraulic actuator leakage fault detection using extended kalman filter. International Journal of Fluid Power, 6(1), pp. 41-51.

Chen, P., Chua, P. S. K., \& Lim, G. H. (2007). A study of hydraulic seal integrity. Mechanical Systems and Signal Processing, 21(2), pp. 1115-1126.

Chen, H., Chua, P., \& Lim, G. (2008). Testing and evaluation of water hydraulic components by acoustic emission and wavelet analysis. Journal of Testing and Evaluation, 36(6), pp. 590.

Eftekharnejad, B., Carrasco, M. R., Charnley, B., \& Mba, D. (2011). The application of spectral kurtosis on acoustic emission and vibrations from a defective bearing. Mechanical Systems and Signal Processing, 25(1), pp. 266-284.

Goharrizi, A.Y. and Sepehri, N., 2010. A wavelet-based approach for external leakage detection and isolation from internal leakage in valve-controlled hydraulic actuators. IEEE Transactions on industrial electronics, 58(9), pp.4374-4384.
Goharrizi, A. Y., Sepehri, N., \& Wu, Y. (2010). A waveletbased approach for diagnosis of internal leakage in hydraulic actuators using on-line measurements. International Journal of Fluid Power, 11(1), pp. 61-69.

Ramachandran, M., \& Siddique, Z. (2018). Statistical Time Domain Feature Based Approach to Assess the Performance Degradation of Rotary Seals. In $A S M E$ 2018 International Mechanical Engineering Congress and Exposition. American Society of Mechanical Engineers Digital Collection.

Ramachandran, M., \& Siddique, Z. (2019). A Data-Driven, Statistical Feature-Based, Neural Network Method for Rotary Seal Prognostics. Journal of Nondestructive Evaluation, Diagnostics and Prognostics of Engineering Systems, 2(2).

Shanbhag, V. V., Rolfe, B. F., Griffin, J. M., Arunachalam, N., \& Pereira, M. P. (2019). Understanding galling wear initiation and progression using force and acoustic emissions sensors. Wear, 436, pp. 202991.

Shanbhag, V., Rolfe, B., \& Pereira, M. (2020). Investigation of Galling Wear Using Acoustic Emission Frequency Characteristics. Lubricants, 8(3), 25.

Tan, A. C., Chua, P. S., \& Lim, G. H. (2000). Condition monitoring of a water hydraulic cylinder by vibration analysis. Journal of Testing and Evaluation, 28(6), pp. 507-512.

Tan, A. C., Chua, P. S., \& Lim, G. H. (2003). Fault diagnosis of water hydraulic actuators under some simulated faults. Journal of Materials Processing Technology, 138(1-3), pp. 123-130.

Tang, H. B., Wu, Y. X. \& Ma, C. X. (2010). Inner leakage fault diagnosis of hydraulic cylinder using wavelet energy. Advanced Materials Research, 139, pp. 25172521.

Terchi, A., \& Au, Y. H. J. (2001). Acoustic emission signal processing. Measurement and Control, 34(8), pp. 240244.

Zhao, X., Zhang, S., Zhou, C., Hu, Z., Li, R., \& Jiang, J. (2015). Experimental study of hydraulic cylinder leakage and fault feature extraction based on wavelet packet analysis. Computers \& Fluids, 106, pp. 33-40.

\section{BIOGRAPHIES}

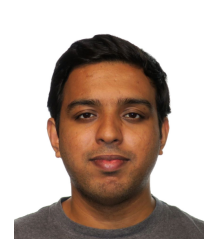

Dr. Vignesh. V. Shanbhag received his M. Tech in Manufacturing Engineering from Vellore Institute of Technology (VIT), India in 2015, and a joint $\mathrm{PhD}$ degree in Manufacturing Engineering from Deakin University (Australia) and Indian Institute of Technology, Madras (IIT-M) in 2019. He currently holds a Postdoc position at NORCE. His research interest includes condition monitoring of machine parts, quantification of machine tool defects using optical profilometer, and nano surface finishing of non-ferrous alloys. 


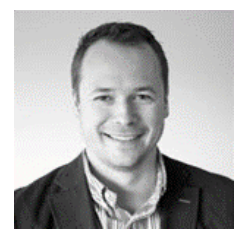

Dr. Thomas. J.J. Meyer is the leader and coordinator of SFI mechatronics projects (Work package 5). Meyer holds a technical university of diploma of physical and chemical measurement technologies from the University of Bordeaux (FRA), a BSc in instrumentation system from Sheffield Hallam University (UK), and a M.Phil. \& PhD in physics from Southampton University (UK). His primary research interest and recent industrial project work at NORCE focuses on the oil and gas industry with topics related to condition-based maintenance, conception of experimental rigs and development of harsh environment proof instrumentation.

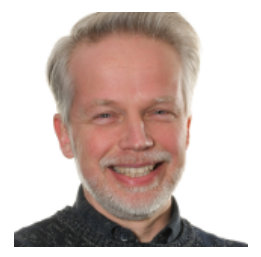

Dr. Leo. W. Caspers got his MSc. in mechanical engineering at Eindhoven University of Technology in 1991. In 1995, he received his $\mathrm{PhD}$ in Engineering Sciences at the same institute. He is currently development manager at Bosch
Rexroth B.V., focusing on the development of tribological systems, piston rod coatings and sensor systems for large hydraulic cylinders.

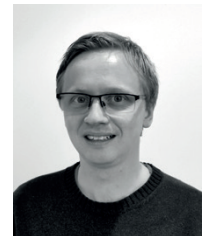

Dr. Rune Schlanbusch received his MSc in Space Technology from Narvik University College (NOR) in 2007, and a $\mathrm{PhD}$ in Engineering Cybernetics from the Norwegian University of Science and Technology (NTNU) in 2012. He currently holds positions as Senior Researcher at NORCE and CTO at Machine Prognostics AS. His research interests include condition monitoring, condition-based maintenance, autonomy, nonlinear stability analysis and control design, rigid body dynamics and Multiphysics modelling and simulation. 